\title{
Effects of exogenous human insulin dose adjustment on body mass index in adult patients with type 1 diabetes mellitus at Kalafong Hospital, Pretoria, South Africa, 2009 - 2014
}

\author{
T S A Sehloho, ${ }^{1,3}$ BPharm, CAHM, MSc (Epi); D G van Zyl, ${ }^{2,3}$ MMed (Int Med), FCP (SA), MSc (Clin Epi), PhD (Int Med) \\ ${ }^{1}$ National Department of Health, Pretoria, South Africa \\ ${ }^{2}$ Department of Internal Medicine, School of Medicine, Faculty of Health Sciences, University of Pretoria, South Africa \\ ${ }^{3}$ School of Health Systems and Public Health, Faculty of Health Sciences, University of Pretoria, South Africa
}

Corresponding author: T S A Sehloho (tohlang.sehloho@health.gov.za)

\begin{abstract}
Background. To maintain fasting blood glucose levels within near to the normal range in type 1 diabetes mellitus (DM), frequent insulin dose adjustments may be required with short-, intermediate- and long-acting insulin formulations. Patients on human insulin generally experience weight gain over time, regardless of the level of glycaemic control achieved.

Objectives. To determine the effects of human insulin, adjusted quarterly to achieve glycaemic control, on body mass index (BMI), and establish dose regimens that achieve optimal glycaemic control without increasing BMI in patients with type 1 DM at the Kalafong Diabetes Clinic in Pretoria, South Africa.

Methods. The sample size ( $N=211,48.8 \%$ male) was obtained by non-probability convenience sampling of all available records of patients with type $1 \mathrm{DM}$ aged $\geq 18$ years at baseline at the clinic. The longitudinal relationships of covariates with time-varying BMI, as well as with time-varying glycated haemoglobin (HbAlc) levels, were explored using multilevel mixed-effects linear regression modelling.

Results. The majority of the patients $(84.8 \%)$ received the twice-daily biphasic human insulin regimen and the remainder received the basal neutral protamine Hagedorn (NPH) plus prandial regular human insulin regimen. The multivariable multilevel mixed-effects linear regression model indicated that time-varying BMI was significantly positively related to time-varying twice-daily biphasic insulin dosage ( $\beta$ (standard error) $0.464(0.190), p=0.015)$, baseline HbAlc $(0.092(0.026), p<0.001)$ and baseline BMI $(0.976(0.016), p<0.001)$. There were significant inverse associations with the number of years spent in the study $(-0.108(0.052), p=0.038)$, time-varying HbAlc $(-0.154(0.031)$, $p<0.001)$ and male sex $(-0.783(0.163), p<0.001)$. There were non-significant negative longitudinal associations of age $(-0.005(0.006)$, $p=0.427)$ and current smoking status $(-0.231(0.218), p=0.290)$ with BMI outcomes.

Conclusions. There was no evidence that optimal quarterly-prescribed daily dosage adjustments of insulin improved and maintained blood glucose control without increasing body weight. When compared with the basal NPH plus prandial insulin regimen, twice-daily biphasic insulin was associated with a statistically significant increase in subsequent BMI. Baseline HbA1c and BMI were also significantly positively associated with time-varying BMI. However, males appeared to be at a lower risk than females of an increase in BMI during insulin therapy. A question for further research is whether the analogue insulins will be associated with the same increase in BMI, as well as the same modest improvements in HbAlc, seen in this sample.
\end{abstract}

S Afr Med J 2017;107(6):528-534. DOI:10.7196/SAMJ.2017.v107i6.12098

The aim of type 1 diabetes mellitus (DM) management is to achieve glycaemic control by frequent exogenous insulin injections. To maintain fasting blood glucose levels within near to the normal range of $3.9-5.6 \mathrm{mmol} / \mathrm{L}$, frequent insulin dose adjustments may be required. Insulin replacement is achieved by short-, intermediateand long-acting insulin formulations, depending on the patient's individual circumstances and the treating healthcare professional's clinical judgement. One clinical strategy of glycaemic control is through intensive insulin therapy (IIT). However, patients on IIT have been observed to experience weight gain over time, regardless of the level of glycaemic control achieved. ${ }^{[1]}$ Several mechanisms have been postulated to account for this, including snacking outside normal mealtimes to offset IIT-associated hypoglycaemia. In addition, anabolic effects of insulin on skeletal muscle, alterations in the regulators of adiposity, and the resolution of glycosuria leading to conservation of calories in previously poorly controlled patients with DM are also hypothesised as mechanisms of weight gain over time in type $1 \mathrm{DM}^{[2]}$

Newer insulin formulations attempt to mimic physiological secretion of insulin by changing the onset and duration of action of insulin. However, these analogues are expensive and not available in the South African (SA) public health sector. The older human insulin formulations used in this setting have less favourable onset and duration of action profiles and are therefore associated with a greater degree of weight gain in most settings. ${ }^{[3]}$

\section{Objective}

To determine the effect of human insulin therapy, adjusted every 3 months to control blood glucose, on body mass index (BMI) in a cohort of type $1 \mathrm{DM}$ patients at the Kalafong Hospital Diabetes Clinic in Pretoria, SA. In addition, the study sought to determine the differential effects of sex on BMI changes in response to exogenous human insulin dose adjustments to control blood glucose levels.

\section{Methods}

The study utilised prospectively collected data on a cohort of type 1 DM patients seen at the clinic for at least 2 years. All patients were clinically managed and data were collected on administrative forms in a structured way. The patients had to be at least 18 years of age on 
first encounter at the clinic and not on metformin and/or acarbose, coexposure to which was considered a potential confounder in the association between exogenous human insulin exposure and BMI changes owing to their potentially weight-reducing effects in other settings. ${ }^{[4,5]}$

Patients were excluded from the study if they failed to attend more than two consecutive or three random non-consecutive scheduled quarterly clinic visits during the period of observation. Patients were assessed at least quarterly between 2009 and 2014. All clinic data, from which individual patient information was extracted, were also routinely captured onto a clinic database. Data were extracted and captured on an Excel spreadsheet (2010, Microsoft, USA) for data cleaning and arrangement. The final dataset was exported to Stata version 12 (StataCorp, USA) for statistical analysis.

\section{Statistical analysis}

The following variables were utilised in the analysis: quarterlyprescribed daily human insulin dosages (IU/kg/d); mean daily human insulin dose exposures (IU/d); type of human insulin regimen prescribed (twice-daily biphasic or basal neutral protamine Hagedorn (NPH) plus prandial normal insulin regimen); measured weight and height (from which time-varying BMI was calculated); baseline weight and time-invariant height (from which baseline BMI was calculated); baseline glycated haemoglobin (HbAlc) level (\%; $\mathrm{mmol} / \mathrm{mol}$ ); time-varying $\mathrm{HbAlc}$ level (\%; $\mathrm{mmol} / \mathrm{mol}$ ) measured semi-annually; sex; age at the onset of the study and going forward; smoking history; and time spent in the study.

Further data management and analysis was carried out using Stata version 12. Baseline patient characteristics were summarised using means and standard deviations (SDs) for continuous variables and frequencies for count variables. The $t$-test and $\chi^{2}$ test (or Fisher's exact test when there were insufficient numbers in cells for the $\chi^{2}$ test, and the Welch test when the equal variance assumption was not satisfied) were used to evaluate differences in baseline characteristics by sex and $\mathrm{HbAlc}$ levels.

The longitudinal relationship of time-varying BMI with timevarying glycaemic control, adjusted for exogenous human insulin replacement and other covariates, was examined by multilevel mixedeffects linear regression analysis, which accounted for the correlated repeated measurements of covariates within subjects.

\section{Ethical approval}

Ethical approval was obtained from the University of Pretoria Institutional Ethics Committee (ref. no. 94/2015). At their first visit, all clinic patients are requested to sign a notification that informs them that routinely collected information at the clinic may be used for research purposes, that all information used is strictly confidential, and that no patient identifiers will be made known. Consent to access routinely collected patient information for this study was obtained from the Kalafong Hospital chief executive officer as the custodian of the clinic data ('Permission to conduct research' letter dated 6 March 2015). All patient information was used anonymously.

\section{Results}

Patient flow, exclusion and inclusion were performed as shown in Fig. 1.

The final sample consisted of 211 patients (108 females and 103 males). The mean (SD) age was 43.1 (14.4) years (range 18 - 78). The mean baseline BMI and $\mathrm{HbAlc}$ for the sample were $27.8(5.5) \mathrm{kg} / \mathrm{m}^{2}$ and $10.2 \%(3.5 \%)$, respectively. Most patients were at $>8.0 \% \mathrm{HbA} 1 \mathrm{c}$ levels at baseline (65.9\%) and most were prescribed the twice-daily biphasic insulin regimen (84.8\%) (Table 1).

Baseline characteristics stratified by sex (Table 2) indicated that females had a higher baseline BMI than males $(p=0.002)$, at a mean

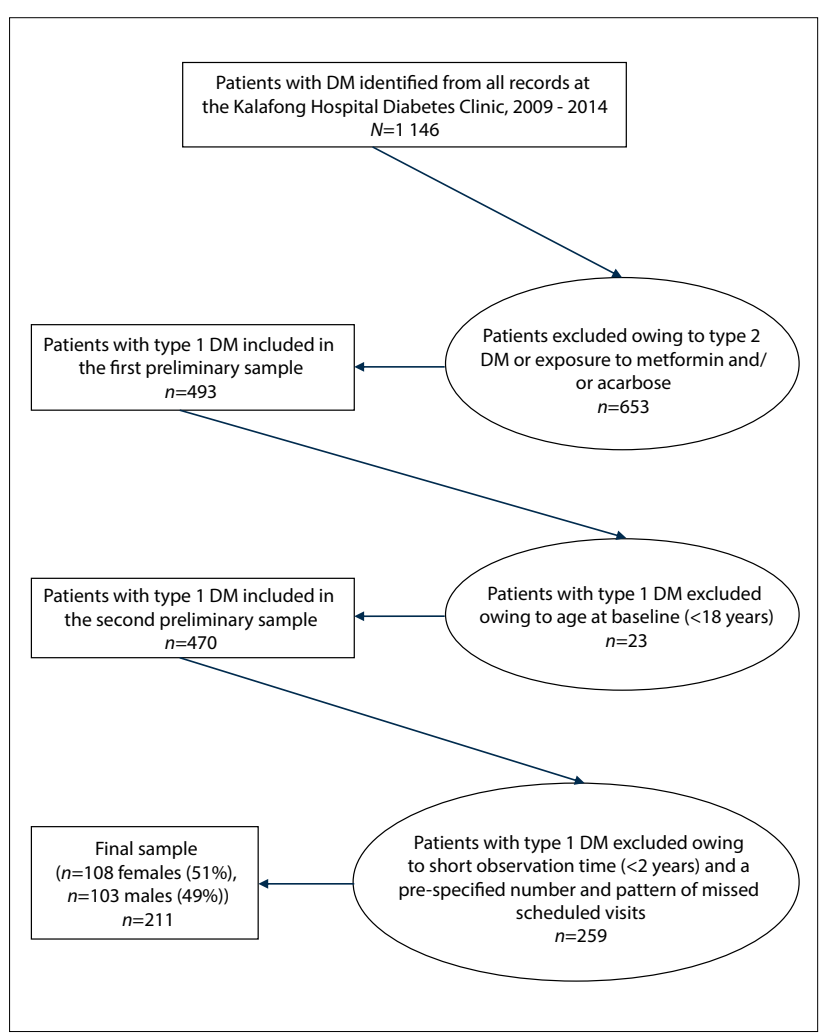

Fig. 1. Patient sampling description for inclusion and exclusion in the study. (DM = diabetes mellitus.)

\begin{tabular}{|c|c|}
\hline Age at first visit (yr), mean (SD) & $43.1(14.4)$ \\
\hline $\begin{array}{l}\text { Duration of type } 1 \mathrm{DM}(\mathrm{yr})(N=131) \text {, } \\
\text { mean }(\mathrm{SD})\end{array}$ & $15.5(7.7)$ \\
\hline Clinic visits $(n)$, mean $(\mathrm{SD})$ & $20.7(6.7)$ \\
\hline Time in study (yr), mean (SD) & $4.7(1.6)$ \\
\hline Weight (kg), mean (SD) & $75.5(15.0)$ \\
\hline BMI $\left(\mathrm{kg} / \mathrm{m}^{2}\right)$, mean $(\mathrm{SD})$ & $27.8(5.5)$ \\
\hline $\operatorname{HbAlc}(\%)$, mean $(\mathrm{SD})$ & $10.2(3.5)$ \\
\hline \multicolumn{2}{|l|}{ BMI category $\left(\mathrm{kg} / \mathrm{m}^{2}\right), n(\%)$} \\
\hline$<19$ & $10(4.7)$ \\
\hline $20-25$ & $66(31.3)$ \\
\hline $25.1-30$ & $73(34.6)$ \\
\hline $30.1-35$ & $44(20.9)$ \\
\hline $35.1-40$ & $14(6.6)$ \\
\hline$>40$ & $4(1.9)$ \\
\hline \multicolumn{2}{|l|}{ HbAlc (\% (mmol/mol)), $n(\%)$} \\
\hline$\leq 8.0(\leq 64)$ & $72(34.1)$ \\
\hline$>8.0(>64)$ & $139(65.9)$ \\
\hline \multicolumn{2}{|l|}{$\begin{array}{l}\text { Mean daily insulin dose and regimen, } \\
\text { mean (SD), } n(\%)\end{array}$} \\
\hline $\begin{array}{l}\text { Basal NPH + prandial regular insulin } \\
(\mathrm{IU} / \mathrm{d})\end{array}$ & $59.8(36.7), 32(15.2)$ \\
\hline Twice-daily biphasic insulin only (IU/d) & $49.4(17.1), 179(84.8)$ \\
\hline \multicolumn{2}{|l|}{ Smoking status, $n(\%)$} \\
\hline $\begin{array}{l}\text { Never smoked or stopped ( }>\text { and } \\
<1 \text { year ago) }\end{array}$ & $174(82.5)$ \\
\hline Currently smoking & $37(17.5)$ \\
\hline
\end{tabular}


(SD) of $28.9(6.2)$ and $26.5(4.4) \mathrm{kg} / \mathrm{m}^{2}$, respectively. Females had a higher baseline HbAlc level than males (mean $10.8 \%$ (3.8\%) v. 9.5\% (3.0\%); $p=0.01$ ), and more males than females were current smokers
$(28.1 \%$ v. $7.4 \% ; p<0.001)$. There were no statistically significant differences by sex in the duration of type $1 \mathrm{DM}$, the number of clinic visits and time of observation in the study (Table 3 ).

Table 2. Baseline characteristics of the patients stratified by sex

\begin{tabular}{|c|c|c|c|}
\hline Variables & Females $(N=108,51.2 \%)$ & Males $(N=103,48.8 \%)$ & $p$-value \\
\hline Age (yr), mean (SD) & $41.9(16.2)$ & $44.3(12.1)$ & 0.222 \\
\hline Height $(\mathrm{cm})$, mean $(\mathrm{SD})$ & $159.8(6.7)$ & $171.3(7.8)$ & $<0.001$ \\
\hline Weight (kg), mean (SD) & $73.6(16.2)$ & $77.5(13.4)$ & 0.063 \\
\hline BMI $\left(\mathrm{kg} / \mathrm{m}^{2}\right)$, mean (SD) & $28.9(6.2)$ & $26.5(4.4)$ & 0.002 \\
\hline HbAlc (\%), mean (SD) & $10.8(3.8)$ & $9.5(3.0)$ & 0.010 \\
\hline BMI category $\left(\mathrm{kg} / \mathrm{m}^{2}\right), n(\%)$ & & & 0.012 \\
\hline$<19$ & $4(3.7)$ & $6(5.8)$ & \\
\hline $20-25$ & $30(27.7)$ & $36(34.9)$ & \\
\hline $25.1-30$ & $31(28.7)$ & $42(40.8)$ & \\
\hline $30.1-35$ & $28(25.9)$ & $16(15.5)$ & \\
\hline $35.1-40$ & $11(10.2)$ & $3(2.9)$ & \\
\hline$>40$ & $4(3.7)$ & $0(0)$ & \\
\hline $\mathrm{HbAlc}(\%(\mathrm{mmol} / \mathrm{mol})), n(\%)$ & & & 0.407 \\
\hline$\leq 8.0(\leq 64)$ & $34(31.5)$ & $38(36.9)$ & \\
\hline$>8.0(>64)$ & $74(68.5)$ & $65(63.1)$ & \\
\hline \multicolumn{4}{|l|}{ Insulin regimen and daily dose, mean (SD), $n(\%)$} \\
\hline Basal NPH + prandial regular insulin (IU/d) & 65.9 (47.5), $17(15.7)$ & $52.9(25.1), 15(14.6)$ & 0.350 \\
\hline Twice-daily biphasic insulin (IU/d) & $48.8(17.7), 91(84.3)$ & $50.1(16.6), 88(85.4)$ & 0.614 \\
\hline Smoking status, $n(\%)$ & & & $<0.001$ \\
\hline Never smoked & $93(86.1)$ & $41(39.8)$ & \\
\hline Stopped $>1$ yr ago & $5(4.6)$ & $27(26.2)$ & \\
\hline Stopped $<1$ yr ago & $2(1.9)$ & $5(4.9)$ & \\
\hline Currently smoking & $8(7.4)$ & $29(28.1)$ & \\
\hline
\end{tabular}

\section{Table 3. Further patient characteristics stratified by sex}

\begin{tabular}{|c|c|c|c|}
\hline Variables & Females $(N=108,51.2 \%)$ & Males $(N=103,48.8 \%)$ & $p$-value \\
\hline Duration of type $1 \mathrm{DM}(\mathrm{yr})(N=131)$, mean $(\mathrm{SD})$ & $16.1(7.9)(n=60)$ & $15.1(7.6)(n=71)$ & 0.457 \\
\hline Clinic visits $(n)$, mean (SD) & $20.1(6.9)$ & $21.3(6.4)$ & 0.218 \\
\hline Time in study (yr), mean (SD) & $4.6(1.7)$ & $4.9(1.5)$ & 0.182 \\
\hline
\end{tabular}

Table 4. Baseline patient characteristics stratified by baseline HbA1c level

\begin{tabular}{|c|c|c|c|}
\hline Variables & $\begin{array}{l}\text { HbA1c } \leq 8.0 \% \\
(N=72,34.1 \%)\end{array}$ & $\begin{array}{l}\text { HbA1c }>8.0 \% \\
(N=139,65.9 \%)\end{array}$ & $p$-value \\
\hline Age (yr), mean (SD) & $44.9(16.0)$ & $42.1(13.4)$ & 0.199 \\
\hline Height $(\mathrm{cm})$, mean $(\mathrm{SD})$ & $166.3(9.3)$ & $164.9(9.1)$ & 0.311 \\
\hline Weight $(\mathrm{kg})$, mean $(\mathrm{SD})$ & $78.8(13.7)$ & $73.8(15.4)$ & 0.023 \\
\hline BMI $\left(\mathrm{kg} / \mathrm{m}^{2}\right)$, mean $(\mathrm{SD})$ & $28.6(5.2)$ & $27.2(5.7)$ & 0.079 \\
\hline Sex, $n(\%)$ & & & 0.407 \\
\hline Female & $34(31.5)$ & $74(68.5)$ & \\
\hline Male & $38(36.9)$ & $65(63.1)$ & \\
\hline \multicolumn{4}{|l|}{ Insulin regimen daily dose, mean (SD) } \\
\hline Basal NPH + prandial regular insulin (IU/d) & $57.1(25.0)$ & $65.4(33.0)$ & $<0.001$ \\
\hline Twice-daily biphasic insulin (IU/d) & $49.4(17.7)$ & $55.6(17.7)$ & $<0.001$ \\
\hline Smoking status, $n(\%)$ & & & 0.045 \\
\hline Never smoked & $41(30.4)$ & $94(69.6)$ & \\
\hline Stopped $>1$ yr ago & $18(56.3)$ & $14(43.7)$ & \\
\hline Stopped $<1$ yr ago & $2(28.6)$ & $5(71.4)$ & \\
\hline Currently smoking & $11(29.7)$ & $26(70.3)$ & \\
\hline
\end{tabular}


There were no significant differences by age, height or sex between patients in the lower and higher baseline HbAlc levels (Table 4). Also stratified by baseline HbA1c level (Table 5), the proportion of patients in the $>8.0 \% \mathrm{HbAlc}$ category was significantly higher for the group with longer duration of type $1 \mathrm{DM}$ (mean (SD) 16.9 (7.7) years (54.2\%) than for those with a shorter onset of type $1 \mathrm{DM}$ at $13.5(7.4)$ years $(45.8 \%)(p=0.014)$. Higher doses of twice-daily biphasic insulin were prescribed to patients at higher baseline HbAlc levels $(>8.0 \%)$ than to those with HbA1c levels of $\leq 8.0 \%$ (mean 55.6 (17.7) IU/d v. 49.4 (17.7) IU/d; $p<0.001$ ). Similarly, higher doses of basal NPH plus prandial regular insulin were prescribed to patients at higher baseline HbAlc levels $(>8.0 \%)$ than to those with HbAlc levels of $\leq 8.0 \%$ (mean 65.4 (33.0) IU/d v. 57.1 (25.0) IU/d; $p<0.001$ ).

Apart from the expected statistically significant and very high correlations between total insulin exposure and exposure to either the biphasic $(r=0.959)$ or basal NPH plus prandial regular insulin regimens $(r=1.000)$ and subsequent BMI and baseline BMI $(r=0.889)$, other correlations were also observed at $p<0.05$. For instance, subsequent $\mathrm{HbA} 1 \mathrm{c}$ and baseline $\mathrm{HbA} 1 \mathrm{c}$ were moderately correlated $(r=0.509)$. The number of clinic visits was dropped from multivariate analysis owing to high correlation with time spent in the study $(r=0.869)$ (Appendix 1).

For multilevel mixed-effects linear regression modelling, the variables of baseline BMI, baseline and time-varying HbAlc and age were modelled as continuous variables. Insulin regimen, sex and smoking history were modelled as categorical variables. The variable smoking history was categorised into two descriptive classes. Age and smoking status in the final reduced model, albeit not statistically significant, contributed favourably to goodness-of-fit characteristics and the lowest information criteria statistics and were therefore included in the final model ${ }^{[6]}$ (Table 6).

Exposure to the twice-daily biphasic insulin regimen, adjusted for other variables including total insulin exposure, was associated with a $0.464 \mathrm{~kg} / \mathrm{m}^{2}(p=0.015)$ increase in subsequent BMI when compared with the basal-bolus insulin regimen. After adjustment for other variables, the BMI increased by $0.009 \mathrm{~kg} / \mathrm{m}^{2}$ for every unit increase of any human insulin per day $(p=0.009)$. After adjustment for other variables, the following covariables: an additional year of observation; every $1.0 \%$ increase in $\mathrm{HbAlc}$ (poor glycaemic control); and being male, were associated with a decrease in BMI ( $\beta$ (standard error)) of $0.108(0.052) \mathrm{kg} / \mathrm{m}^{2}(p=0.038), 0.154(0.031) \mathrm{kg} / \mathrm{m}^{2}(p<0.001)$ and $0.783(0.163) \mathrm{kg} / \mathrm{m}^{2}(p<0.001)$, respectively. However, every $1 \mathrm{~kg} / \mathrm{m}^{2}$ higher baseline BMI predicted a $0.98 \mathrm{~kg} / \mathrm{m}^{2}$ increase in subsequent BMI. Every $1.0 \%$ higher baseline $\mathrm{HbAlc}$ predicted a $0.09 \mathrm{~kg} / \mathrm{m}^{2}$ increase in subsequent BMI (Table 6). Adjusted increasing age and current smoking status were associated with statistically nonsignificant reductions in subsequent BMI in this cohort of -0.005 $(0.006)(p=0.427)$ and $-0.231(0.218)(p=0.290)$, respectively.

\section{Discussion}

This study described longitudinal associations of time-varying BMI with exposure to quarterly-prescribed daily insulin dosage regimens in an attempt to achieve optimal blood glucose control in a sample of patients with type $1 \mathrm{DM}$ at the Diabetes Clinic at Kalafong Hospital,

Table 5. Further patient characteristics stratified by baseline HbAlc level

\begin{tabular}{llll}
\hline Variables & HbA1c $\leq \mathbf{8 . 0 \%}(\mathbf{N = 7 2 , 3 4 . 1 \% )}$ & HbA1c >8.0\% $(\mathbf{N = 1 3 9 , 6 5 . 9 \% )}$ & $\boldsymbol{p}$-value \\
\hline Duration of type 1 DM $(\mathrm{yr})(\mathrm{N}=131)$, mean $(\mathrm{SD})$ & $13.5(7.4)(n=60)$ & $16.9(7.7)(n=71)$ & 0.014 \\
Clinic visits $(n)$, mean $(\mathrm{SD})$ & $22.4(6.1)$ & $19.8(6.8)$ & 0.007 \\
Time in study $(\mathrm{yr})$, mean $(\mathrm{SD})$ & $5.2(1.5)$ & $4.5(1.7)$ & 0.003 \\
HbAlc = glycated haemoglobin; DM = diabetes mellitus; SD = standard deviation. & & &
\end{tabular}

\section{Table 6. Regression models by time-varying BMI value}

\begin{tabular}{|c|c|c|c|c|}
\hline \multirow[b]{2}{*}{ Time-varying BMI value covariates } & \multicolumn{2}{|c|}{ Univariate models } & \multicolumn{2}{|c|}{ Multivariate model } \\
\hline & $\beta$ (SE) & $p$-value & $\beta(\mathrm{SE})$ & $p$-value \\
\hline Age & $0.142(0.007)$ & $<0.001$ & $-0.005(0.006)$ & $0.427^{\star}$ \\
\hline Baseline BMI $\left(\mathrm{kg} / \mathrm{m}^{2}\right)$ & $0.983(0.009)$ & $<0.001$ & $0.976(0.016)$ & $<0.001$ \\
\hline Time-varying HbAlc (\%) & $-0.333(0.061)$ & $<0.001$ & $-0.154(0.031)$ & $<0.001$ \\
\hline Baseline HbA1c (\%) & $-0.151(0.031)$ & $<0.001$ & $0.092(0.026)$ & $<0.001$ \\
\hline Number of clinic visits & $-0.046(0.018)$ & 0.010 & $\begin{array}{l}\text { Dropped owing to collinearity } \\
\text { with time in study }\end{array}$ & \\
\hline Time in study & $0.022(0.014)$ & 0.128 & $-0.108(0.052)$ & 0.038 \\
\hline \multicolumn{5}{|l|}{ Sex } \\
\hline $0=$ female & Ref & & Ref & \\
\hline $1=$ male & $-3.262(0.203)$ & $<0.001$ & $-0.783(0.163)$ & $<0.001$ \\
\hline \multicolumn{5}{|l|}{ Insulin regimen } \\
\hline $0=$ basal NPH + prandial regular insulin (IU/day) & Ref & & Ref & \\
\hline $1=$ twice-daily biphasic insulin (IU/d) & $2.664(0.257)$ & $<0.001$ & $0.464(0.190)$ & 0.015 \\
\hline Total insulin exposure (IU/d) & $0.029(0.005)$ & $<0.001$ & $0.009(0.003)$ & 0.009 \\
\hline \multicolumn{5}{|l|}{ Smoking status } \\
\hline $0=$ never smoked and stopped $>$ or $<1 \mathrm{yr}$ ago & Ref & & Ref & \\
\hline $1=$ currently smoking & $-2.251(0.293)$ & $<0.001$ & $-0.231(0.218)$ & $0.290^{*}$ \\
\hline Constant & $\mathrm{n} / \mathrm{a}$ & & $2.111(0.667)$ & 0.002 \\
\hline $\begin{array}{l}\text { Multivariate model information criteria statistics: } \\
\text { Model AIC }=5628.996 \text { (v. } 5729.69 \text { without the 'age' and 'smoking' varia } \\
\text { Model BIC = } 5684.904 \text { (v } 5775.59 \text { without the 'age' and 'smoking' varia } \\
\text { BMI = body mass index; SE = standard error; HbA1C = glycated haemo } \\
\text { *Statistically non-significant covariates included in the final multivariab }\end{array}$ & $\begin{array}{l}\text { model). } \\
\text { model). } \\
\text { = neutral protamine } \mathrm{I}\end{array}$ & $\mathrm{n} / \mathrm{a}=$ & $\begin{array}{l}\text { ble. } \\
\text { ria statistics. }\end{array}$ & \\
\hline
\end{tabular}


Pretoria. Sex differences in outcomes of exogenous human insulin replacement therapy were also investigated.

On multivariable multilevel linear mixed-effects regression analysis, there was no evidence that optimal quarterly-prescribed daily dosage increases of insulin safely improved and maintained blood glucose control without increasing body weight. Both regimens consistently and independently increased weight, particularly in female patients, without clinically significantly improving blood glucose control. ${ }^{[7]}$ The study also found that higher baseline BMI and $\mathrm{HbAlc}$ predicted weight gain regardless of insulin regimen.

There were significant sex differences in the change in body weight on exposure to any insulin used to control blood glucose to optimal levels. Male patients tended to experience reductions in time-varying BMI on exposure to the twice-daily biphasic human insulin regimen, after adjustment for the other variables in the model. Twice-daily human insulin was the treatment regimen prescribed for $84.8 \%$ of patients in this cohort and was proportionally distributed the same in both males and females.

The study did not find a balance between optimal glycaemic control and prevention of weight gain. Instead, exposure to human insulin to achieve glycaemic control consistently predicted weight gain in the cohort observed. However, in a 2010 review, Hahr and Molitch $^{[8]}$ observed that optimal glycaemic control in type $1 \mathrm{DM}$ patients depended on an insulin regimen that closely mimicked endogenous insulin secretion. The study found that this was best achieved with long-acting basal insulin to maintain normal fasting glucose levels, and multiple daily injections of short- or rapidacting (prandial) insulin with meals. Furthermore, the choice of regimen depended on the individual needs and circumstances of the patient, as well as the treating health professional's judgement. ${ }^{[8]}$ This assertion was consistent with that of Fullerton et al. ${ }^{[9]}$ that there was then (in 2014) no firm evidence for specific blood glucose targets, therefore necessitating individualised therapeutic goals that take into account the patient's age, disease progression, macrovascular risk, lifestyle and disease self-management capabilities. The reviewers also concluded that patient-specific regimens to optimise glycaemic control have been made possible by the development of insulin analogues, which increase flexibility and control in the treatment of type 1 DM. Also, because IIT with basal NPH and prandial human insulin requires multiple daily injections, it was crucial that health workers communicate therapy-related issues to patients. These issues include lifestyle adjustments and exercise, meal intake and its effects, proper insulin self-administration, and the effects of insulin dose adjustments not based on reliable blood glucose readings. ${ }^{[9]}$ These therapy-related issues ${ }^{[8,9]}$ were found to be adequately addressed in the Kalafong Diabetes Clinic practice.

The current study concluded that exposure to adjusted doses of human insulin to achieve optimal glycaemic control in patients with type 1 DM resulted in a statistically significant increase in BMI. This relationship seemed to be more prominent in female patients and in patients with higher baseline HbAlc levels and BMI categories. Conclusions can also be drawn that an increase in BMI is consistent with improvements in blood glucose control in this setting. Also, strategies already in place at the Kalafong Diabetes Clinic to control weight gain through advice on physical exercise, dietary and lifestyle counselling as part of clinical management should continue and be strengthened further to sustain optimal BMI outcomes in type 1 DM patients in this setting.

The finding that a higher baseline HbAlc predicted a larger and statistically significant increase in subsequent BMI in patients exposed to the twice-daily biphasic insulin dosage regimen when compared with the basal NPH plus prandial regular insulin regimen group in this study population was consistent with observations by Nansel et al., ${ }^{[10]}$ Williams et al. ${ }^{[11]}$ and Conway et al. ${ }^{[1]}$ These researchers found that IIT and a higher baseline HbAlc were predictors of weight gain in patients in their respective settings. The current study also identified any insulin exposure adjusted for other covariates and baseline BMI to be significant predictors of weight gain in the cohort of patients observed. These findings are consistent with those of Conway et al. ${ }^{[1]}$ in a longitudinal study to determine the prevalence and incidence of overweight and obesity in a cohort of 589 type $1 \mathrm{DM}$ patients followed up over at least 18 years.

The Diabetes Control and Complications Trial cited in the review by Kaufman ${ }^{[2]}$ also demonstrated the association between excess weight gain and IIT. The risk factors suggested by the review include oral glucose ingestion to offset hypoglycaemia, the fear of nocturnal hypoglycaemia resulting in night-time snacking, the anabolic effect of insulin on skeletal muscle mass, and alteration in the leptinmediated regulators of lipolysis and lipogenesis, ${ }^{[2]}$ also resulting in resistance to the antilipolytic actions of insulin. ${ }^{[12]}$ Conservation of calories in previously poorly controlled diabetic patients is hypothesised as another mechanism of weight gain in patients with type $1 \mathrm{DM}$. According to this hypothesis, this conservation of ingested calories occurs when glycosuria is resolved with improved glycaemic control during IIT to blood glucose levels below the renal secretion threshold. ${ }^{[2]}$

Where the results of this study may not be wholly consistent with those of other published studies on the topic, Nansel et al. ${ }^{[10]}$ advise that most differences of associations between studies can be attributed to differences in sample characteristics, study designs and statistical analytical methods. They also found the association between BMI and glycaemic control to be complex, highlighting the need for longitudinal study designs and appropriate analyses to account for the time-dependent direction of causation of the observed association. The current longitudinal multilevel study design has attempted to characterise that complex relationship in the observed sample of patients.

This was an observational study of primary data routinely collected for clinical management of patients with type $1 \mathrm{DM}$ in a clinic setting. The data were therefore not collected explicitly for answering the research question. As a result, there were a number of missing measurements, either not recorded or not measured. The variable most affected was weight measurements at each quarterly visit, which was manually observed to follow an 'item non-response' missingness distribution. ${ }^{[13]}$ This variable was, however, not imputed for randomly missing data, but was rather analysed as is without the $27.6 \%$ missing measurements, to avoid possible measurement bias. It is therefore highly probable, based on the literature, that the observed magnitude of BMI increase in this sample was underestimated by the missing $27.6 \%$ quarterly-repeated weight measurements in the sample.

The study was also not conducted on newly diagnosed or previously untreated patients. An inception cohort with only newly diagnosed patients in the study would have avoided 'prevalent user bias' introduced by 'survivors' of the time-varying effects on BMI of pre-observation exposure to human insulin. ${ }^{[14]}$ Together, these limitations could have attenuated the observed BMI effects of insulin in this sample. Also, findings from the current study are limited to a single ethnic and demographic group of black African patients and may therefore not be generalisable beyond those confines.

Unmeasured covariates at the beginning of exposure to human insulin in this cohort were probably subsequently affected by the exposure itself. ${ }^{[14]}$ For instance, patients may have changed their dietary habits after diagnosis, which would be expected to impact on BMI outcomes in variable ways. When not measured and adjusted 
for, this covariate could be expected to confound the true change in measured subsequent BMI. This limitation is consistent with that recognised in the Nansel et al. s $^{[10]}$ study that no diet or physical activity data were available to determine their contribution to timevarying BMI in particular.

Many regression models in epidemiological (and clinical) research are replete with instances of collinearity. ${ }^{[15]}$ This is because many observed covariates often 'share common physiological mechanisms or measure different aspects of the same underlying mechanism. ${ }^{\text {'[15] }}$ However, despite the observed sign reversals and evidence of mediation seen from the univariate to the multivariate models in Table 6, exploration of the impact of multicollinearity on the modelling process was beyond the scope of the current study and was not undertaken. However, owing to collinearity between the number of patient visits to the clinic and the number of years of follow-up in the study, the number of patient visits to the clinic was excluded from the final model. This decision served to prevent too much explanatory redundancy introduced by including two clearly collinear time-based explanatory covariables in the model. ${ }^{[16]}$

\section{Conclusion}

Based on the literature reviewed for this study, there does not seem to be a dosage range at which optimal glycaemic control can be achieved easily without an increase in body weight. Rather, optimal glycaemic control, through adjustments of exogenous insulin replacement therapy based on measured $\mathrm{HbAlc}$ levels, appears to be a consistent and independent predictor of an increase in body weight. Regular attendance of scheduled clinic visits may be advisable to ensure better BMI outcomes, especially in females. It could also be advised that BMI increase may not necessarily be bad for HbAlc control, but should be tightly controlled through exercise and dietary advice, and closely monitored to prevent relevant comorbidities.

No patients in this study were on analogue insulins. These include the rapid-acting aspart, lispro and glulisine analogues, the long-acting basal glargine and detemir analogues, and the premixed insulin analogue formulations. These types of insulin have been formulated to more closely mimic a normal insulin release profile. ${ }^{[3]}$ However, the DM treatment protocol at Kalafong Hospital is similar to that currently in other SA government hospitals in that only human insulins are available, and not the more physiologically compatible analogue insulins. These analogues may be much better than the traditional human insulin currently used in the Kalafong Diabetes Clinic with regard to weight gain. Successful management of type $1 \mathrm{DM}$ relies on how closely the prescribed regimen mimics normal physiological insulin release patterns. ${ }^{[3]}$ A question for further research is whether the analogue insulins will result in the same increase in BMI, as well as the same modest improvements in HbA1c, seen in this sample.

Acknowledgements. The authors wish to acknowledge the contributions of the administrative, medical and nursing staff at the Kalafong Diabetes Clinic. The dissertation supervisor and co-author of this study, Prof. D G van $\mathrm{Zyl}$, is acknowledged for his support and making available the primary data from the Kalafong Diabetes Clinic. Ms L Dzikiti of the University of Pretoria is acknowledged for her advice on the most appropriate statistical approach to adopt in answering questions of longitudinal multilevel mixed-effects associations.

Author contributions. TSAS conducted and wrote up the study for purposes of a master's degree in epidemiology. DGvZ supervised the study and advised on how some of the clinical content would be best presented. Funding. None.

Conflicts of interest. None.

1. Conway B, Miller RG, Costacou T, et al. Temporal patterns in overweight and obesity in type 1 diabetes. Diabet Med 2010;27(4):398-404. http://dx.doi.org/10.1111/j.1464-5491.2010.02956.x

2. Kaufman FR. Consequences of weight gain associated with insulin therapy in adolescents. Endocrinologist 2006;16(3):155-162. http://dx.doi.org/10.1097/01.ten.0000217883.47474.84

3. Hartmann I. Insulin analogs: Impact on treatment success, satisfaction, quality of life, and adherence. Clin Med Res 2008;6(2):54-67. http://dx.doi.org/10.3121/cmr.2008.793

4. Yanofski JA, Krakoff J, Salaita CG, et al. Effects of metformin on body weight and body composition in obese insulin-resistant children: A randomized clinical trial. Diabetes 2011:60(2):477-485. http:// dx.doi.org/10.2337/db10-1185

5. Willms B, Ruge D. Comparison of acarbose and metformin in patients with type 2 diabetes mellitus insufficiently controlled with diet and sulphonylureas: A randomized, placebo-controlled study. Diabet Med 1999;16(9):755-761. http://dx.doi.org/10.1046/j.1464-5491.1999.00149x

6. Vrieze SI. Model selection and psychological theory: A discussion of the differences between the Akaike Information Criterion (AIC) and the Bayesian Information Criterion (BIC). Psychol Methods Akaike Information Criterion (AIC) and the Bayesian Inf
2012;17(2):228-243. http://dx.doi.org/10.1037/a0027127

7. Diabetes Control and Complications Trial Research Group. The effect of intensive treatment of diabetes Diabetes Control and Complications Trial Research Group. The effect of intensive treatment of diabetes
on the development and progression of long-term complications in insulin-dependent diabetes on the development and progression of long-term complications in insulin-dependent diabet
mellitus. N Engl J Med 1993;329(14):977-986. http://dx.doi.org/10.1056/NEJM199309303291401

8. Hahr AJ, Molitch ME. Optimizing insulin therapy in patients with type 1 and type 2 diabetes mellitus: Optimal dosing and timing in the outpatient setting. Dis Mon 2010;56(3):148-162. http://dx.doi. org/10.1016/j.disamonth.2009.12.009

9. Fullerton B, Jeitler K, Seitz M, Horvath K, Berghold A, Siebenhofer A. Intensive glucose control versus conventional glucose control for type 1 diabetes mellitus. Cochrane Database Syst Rev 2014, Issue 2. Art. No.: CD009122. http://dx.doi.org/10.1002/14651858.CD009122.pub2

10. Nansel TR, Lipsky LM, Iannotti RJ. Cross-sectional and longitudinal relationships of body mass index with glycemic control in children and adolescents with type 1 diabetes mellitus. Diabetes Res Clin Pract 2013;100(1):126-132. http://dx.doi.org/10.1016/j.diabres.2012.12.025

11. Williams KV, Erbey JR, Becker D, Orchard TJ. Improved glycemic control reduces the impact of weight gain on cardiovascular risk factors in type 1 diabetes: The Epidemiology of Diabetes Complications gain on cardiovascular risk factors in type 1 diabetes: The Epidemiology of Diabetes
Study. Diabetes Care 1999;22(7):1084-1091. https://doi.org/10.2337/diacare.22.7.1084

12. Duncan RE, Ahmadian M, Jaworski K, Sarkadi-Nagy E, Sook Sul H. Regulation of lipolysis in 2. Duncan RE, Ahmadian M, Jaworski K, Sarkadi-Nagy E, Sook Sul H. Regulation of lipolysis in
adipocytes. Annu Rev Nutr 2007;27:79-101. http://dx.doi.org/10.1146/annurev.nutr.27.061406.093734

3. Allison PD. Missing Data. Quantitative Applications in the Social Sciences, Vol. 136. Thousand Oaks, Calif.: Sage Publishing, 2002:72-89.http://dx.doi.org/10.4135/9780857020994.n4
C.ison PD. Missing Data. Quantitative Applications in the Social Science, Vl.

14. Ray WA. Evaluating medication effects outside of clinical trials: New-user designs. Am J Epidemiol 2003;158(9):915-920. http://dx.doi.org/10.1093/aje/kwg231

15. Woolston A, Tu Y-K, Gilthorpe MS, Baxter PD. Measuring the impact of collinearity in epidemiological research. Int J Stat Probab 2013;2(2):1-11. http://dx.doi.org/10.5539/ ijsp.v2n2p1

16. Yoo W, Mayberry R, Bae S, Singh K, He QP, Lillard JW Jnr. A study of the effects of multicollinearity in multivariable analysis. Int J Appl Sci Technol 2014;4(5):9-19.

Accepted 16 March 2017. 


\section{Appendix 1}

Covariable pairwise correlation matrix analysis

\begin{tabular}{|c|c|c|c|c|c|c|c|c|c|c|c|c|}
\hline & A & B & $\mathrm{C}$ & D & $\mathbf{E}$ & $\mathbf{F}$ & G & $\mathbf{H}$ & I & $\mathbf{J}$ & $\mathbf{K}$ & $\mathbf{L}$ \\
\hline A & 1.000 & & & & & & & & & & & \\
\hline B & 0.889 & 1.000 & & & & & & & & & & \\
\hline $\mathrm{C}$ & & & 1.000 & & & & & & & & & \\
\hline $\mathrm{D}$ & -0.155 & -0.155 & -0.119 & 1.000 & & & & & & & & \\
\hline $\mathrm{E}$ & -0.086 & -0.175 & -0.194 & 0.509 & 1.000 & & & & & & & \\
\hline $\mathrm{F}$ & & & 0.869 & -0.132 & -0.224 & 1.000 & & & & & & \\
\hline G & -0.274 & -0.200 & 0.168 & & -0.143 & 0.091 & 1.000 & & & & & \\
\hline $\mathrm{H}$ & -0.116 & -0.103 & -0.052 & & & & 0.405 & 1.000 & & & & \\
\hline I & 0.349 & 0.413 & 0.072 & -0.194 & -0.018 & 0.090 & 0.099 & 0.092 & 1.000 & & & \\
\hline $\mathrm{J}$ & 0.105 & 0.084 & 0.084 & 0.094 & 0.065 & & & 0.062 & & 1.000 & & \\
\hline $\mathrm{K}$ & 0.116 & 0.104 & 0.080 & & & 0.072 & & 0.076 & 0.087 & 0.959 & 1.000 & \\
\hline $\mathrm{L}$ & & -0.448 & & & & & -0.488 & -0.449 & & 1.000 & 0.493 & 1.000 \\
\hline
\end{tabular}

A = body mass index (BMI); B = base BMI; C = clinic visits; $\mathrm{D}=$ glycated haemoglobin (HbAlc); E = base HbAlc, F = time in study; $\mathrm{G}=$ sex; $\mathrm{H}=$ smoking status; $\mathrm{I}=$ age; $\mathrm{J}=$ total insulin; $\mathrm{K}=$ biphasic insulin; $\mathrm{L}=$ basal plus prandial insulin.

Only $r$-values significant at $p<0.05$ are shown. 